\title{
Natural Disaster Identification and Mapping of Tsunami and Earthquake in Indonesia using Satellite Imagery Analysis (Case Study: Aceh, Palu, and Yogyakarta)
}

\author{
M Rifqi Jundullah ${ }^{1}$, Arie Wahyu Wijayanto ${ }^{2 *}$ \\ 1,2 Politeknik Statistika STIS, Jakarta 13330, Indonesia \\ Corresponding e-mail: ariewahyu@stis.ac.id
}

\begin{abstract}
Remote sensing technology, especially using satellite images, has become essential support in many aspects of decision-making, particularly in disaster risk management. It requires a shorter period of data updates and less cost compared to conventional field observations and surveys. Yet, the intensive processing and high-powered computing resources are necessary to analyze satellite imagery data through Geographic Information System (GIS). In this paper, we introduce the identification and mapping of natural disaster impact in Indonesia using the open-source collaborative tool of Google Earth Engine (GEE) application which analyzes the relative temporal difference of Earth surface from three major satellite images: Sentinel-1, Sentinel-2, and Landsat8. Taking the advantage of the geographical, geological, and demographic conditions of Indonesia's disaster-prone areas, we analyze relative difference from normalized difference vegetation index (NDVI) out of months before and after natural disaster occurrence to measure the impact of natural disaster in focus study areas. Given the high-vegetation nature of three main natural disaster impacted areas in Indonesia: Aceh, Palu, and Yogyakarta, we are able to simplify the analysis by highlighting areas with vegetative loss or gain after the event. Using an open-source GEE application, namely HazMapper, we identify and visualize the aftermath of the tsunami disaster in Aceh and Palu as well as the earthquake in Yogyakarta. Our study is potentially beneficial for government and decision-makers to utilize publicly available satellite images for disaster recovery and mitigation policy.
\end{abstract}

Keyword: satellite images, disaster mapping, GIS

\section{INTRODUCTION}

One of the geological influences for Indonesia is the geological condition of the region which makes Indonesia a country that is prone to disasters. Indonesia is an archipelagic country located between the world's tectonic plates, the Indo-Australian plates in the south, the Pacific Ocean plate in the east, and the Euro-Asia plate in the north. The interaction of tectonic plates can cause tidal waves if they occur in the ocean that cause earthquakes. Earthquakes could be followed by tsunamis, considering that Indonesia is an area that is strongly influenced by the movement of 
these plates, which affects the area near the coast (BNPB, 2015). Some of the worst seismical disasters in Indonesia were the earthquake in Yogyakarta, also tsunami in Aceh and Palu which caused many victims, material losses, and significant damage to regional infrastructure and the environment.

Seeing the geological and geographical conditions of Indonesia, it is necessary to carry out disaster risk management efforts, starting with identifying areas affected by natural disasters. Determining the location of coverage in the field requires a lot of time and money because access is limited and difficult to reach due to the disaster. In the case of a tsunami with a very large affected area, the manual method takes months to years only for the complete identification process of the affected area. Therefore, remote sensing methods are an alternative not only to identify disaster-affected areas, but also to do a descriptive mapping of the severity in each area.

One of the impacts of environmental changes caused by disasters is vegetation. From the post-disaster vegetation regrowth cycle, relative difference in the normalized difference vegetation index (NDVI) can be calculated as rdNDVI in the interest of comparing the greenery flora loss or gain between before and after a natural disaster event in an area. Google Earth Engine (GEE), a planetary-scale platform for geospatial data analysis powered by Google's cloud infrastructure (Robinson, 2017), is utilized using an internet browser to take advantage of data repository, preprocessing, through visualization via cloud computing.

Hazard Mapper (HazMapper) is a GEE open-access application associated for scientific and the emergency management communities focused on the open-source mapping over rapid characterization of global natural hazards. HazMapper is useful for tracking changes in the landscape caused by the destruction or regeneration of terrestrial vegetation as a result of natural disasters or human activities. Non-vegetated settings are not currently supported by the platform. In consequence, the HazMapper tool is very suitable for study cases in Indonesia, which is an agricultural country with a fairly dominant vegetation area to identify and map an event of natural disaster using satellite imagery data analysis.

\section{PRELIMINARIES}

Satellite images are rich in information of geospatial features of the Earth surface, including the spatial, spectral,and multi-temporal information of any region (Nurmasari, 2021; Putri, 2021; Saadi, 2021). Geospatial analysis is often used in the process of extracting information and analyzing well-defined algorithms (Triscowati, 2019; Triscowati, 2020; Wijayanto, 2020). The emergence of publicly available remote sensing data, inclusing satellite imageries, is potentially beneficial for disaster mapping and identification (Ge, 2020; Kucharczyk, 2021).

Information extraction comes from spectral band values for each pixel unit in the image. Vegetation index obtained by merging multiple spectral bands on a precised region. NDVI combines Near Infrared (NIR) and Red band and helps to detect live vegetation. The relative difference in the NDVI (rdNDVI) is used from pre and post-months of natural disaster occurrence to identify the impact of natural disaster on vegetation in the study area. 


$$
\begin{gathered}
N D V I=\frac{\rho N I R-\rho R E D}{\rho N I R+\rho R E D} \\
\operatorname{rdNDVI=}\left(\frac{\text { NDVIpost }- \text { NDV }}{\sqrt{\text { NDVIpre }+ \text { NDVIpos }}}\right) \times 100
\end{gathered}
$$

Traditional GIS method in calculating individual pre/post difference rasters to hazard mapping is time and computationally intensive. The preprocessing of downloading satellite data routine, from dataset cleaning as cloud could interrupt the image to local machine processing with GIS tools (e.g. ArcGIS \& Python) requires a high-powered computer to access and perform by trained analysts. A competent method for identifying, collecting, integrating, processing, analyzing, disseminating, and visualizing a massive amount of data quickly via online computing is required to provide assortment of management decisions, especially a prompt response to an urgent incident. On May 28, 2008, the Google Earth API was introduced and the rapid GIS method was feasible for academic and research use. (2018, Liu).

HazMapper derives a map of a natural disaster event based on users specified input parameters (Table 1). HazMapper utilizes GEE to facilitate geospatial data processing for opensource natural disasters applications. It is principally customized to noticing vegetated-scene change as an intermediary for normal peril impacts. The methodology is novel, utilizing the force of Google Earth Motor to democratize change discovery from multispectral satellite symbolism in a UI intended for analysts, crisis responders, and the deductively inquisitive public. HazMapper doesn't expect clients to download any datasets; have a foundation in information examination, programming improvement, or coding; or approach particular programming other than a web program. Furthermore on the grounds that handling happens from a distance, low-controlled PCs (e.g., Google Chromebooks), tablet PCs, and even cell phones are appropriate for use with HazMapper, albeit the little screen size of such gadgets is a limit.

Table 1. HazMapper input variables, definitions, and examples.

\begin{tabular}{lll}
\hline Input variables & Definition & Example \\
\hline Data source & $\begin{array}{l}\text { Sentinel-2, Landsat 7, or Landsat 8 data sets } \\
\text { are being used for this study. }\end{array}$ & $\begin{array}{l}\text { Sentinel-2 }(10 \mathrm{~m}) \\
2015+\end{array}$ \\
\hline Date & $\begin{array}{l}\text { Dates of earthquakes, tsunamis, and other } \\
\text { natural disasters }\end{array}$ & 28 September 2018 \\
\hline Pre-event & $\begin{array}{l}\text { The period of months to utilize before the } \\
\text { event to obtain the greenest pixel-by-pixel } \\
\text { circumstances. }\end{array}$ & 12 \\
\hline
\end{tabular}




\begin{tabular}{lll}
\hline Input variables & Definition & Example \\
\hline Post-event & $\begin{array}{l}\text { The period of months to utilize after the event } \\
\text { to obtain the greenest pixel-by-pixel } \\
\text { circumstances. }\end{array}$ & 3 \\
\hline cloud cover & $\begin{array}{l}\text { Cloud-cover percent is encoded in the } \\
\text { metadata for each Landsat or Sentinel scene; } \\
\text { the maximum percentage of a scene shrouded } \\
\text { by clouds and yet used in the analysis. }\end{array}$ & \\
\hline Slope & $\begin{array}{l}\text { A topographic slope threshold value in } \\
\text { degrees, at which the data visualization will be } \\
\text { filtered; this is useful for excluding } \\
\text { hydrological features such as lakes and } \\
\text { neighboring oceans in coastal zones. }\end{array}$ & \\
\hline
\end{tabular}

Figure 1 is the recommended workflow for HazMapper usage. Starting with the users to define a region of interest on GEE. Choosing satellite remote sensing datasets from the available selection consist of Sentinel-2, Landsat 8, and Landsat 7. As the intended event date may not be available in the chosen dataset, users can change the dataset in ease through the parameters on the right corner (Figure 1). Pre and post window length need to be adjusted because it directly affects the rdNDVI calculation, e.g. if the post length was too long the area may have recovered and the vegetation loss can not be reliable. Maximum Cloud Cover by default is $30 \%$ but still can be adjusted by the users, as well as slope threshold to get a better visualization.

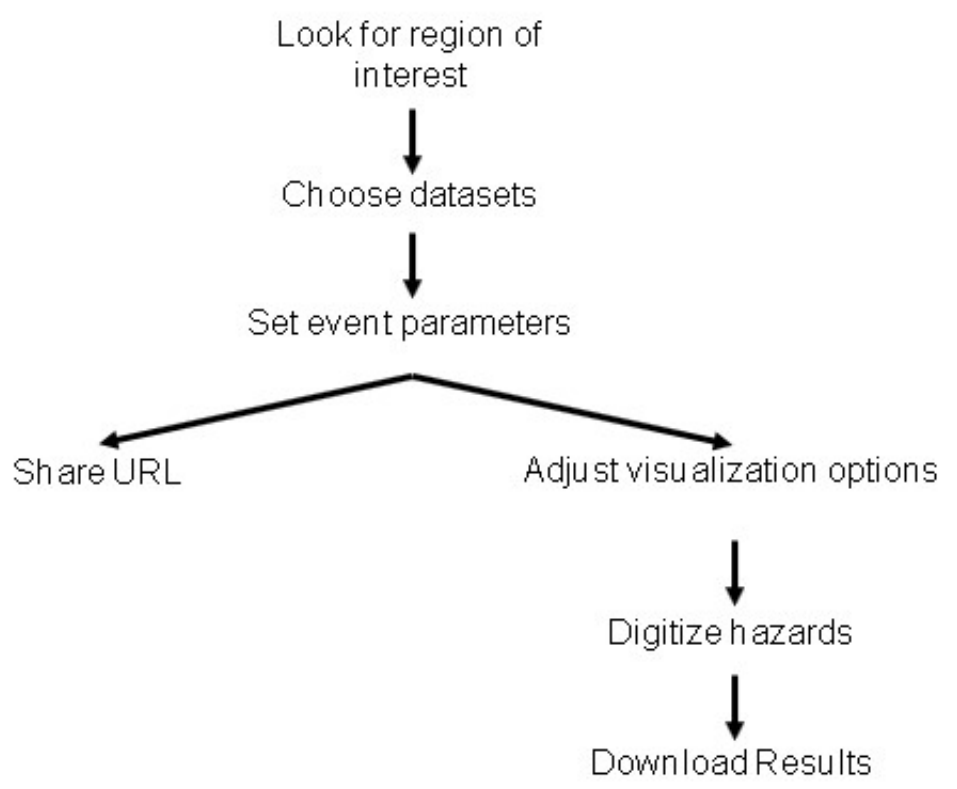

Figure 1. HazMapper Workflow 
The decision point where you can share the URL or proceed adjusting visualization by toggling transparency basemap, digitize hazards with point, lines, and polygons and finally download results of rdNDVI, greenest pre/post images, and elevation data to the available formats.

\section{EXPERIMENTAL RESULTS - INDONESIA CASE STUDY}

The three case studies in Indonesia regarding tsunami and earthquake disasters available in the tools are described in this chapter. The purpose of these case studies is to highlight diverse applications of the rdNDVI cloud-computing method rather than to provide a comprehensive study of the events.

\subsection{Tsunami Disaster in Aceh}

The tsunami which was generated by a powerful earthquake in the Indian Ocean through 2004 had a massive damage on the coastal regions, including severe damage to the ecosystem, destruction of housing as well as other buildings, lakes and farmlands, infrastructures, economic growth, environmental damage of waterbodies, tsunami disposal, etc. (Rosyidie, 2006).

According to Meteorology, Climatology, and Geophysical Agency of Indonesia (BMKG), The devastating earthquake measuring 9.1 on the Richter, $25 \mathrm{~km}$ northwest of Aceh was triggered by a tectonic cause. It was the emergence of a series of massive aftershocks along the AndamanNicobar Megathrust line after the main earthquake. In addition to the coastal areas, rdNDVI captured vegetation loss obtained along the city of Banda Aceh. The rdNDVI results represent severe damage caused by tsunami waves and water flood through miles from shore (Figure 2).

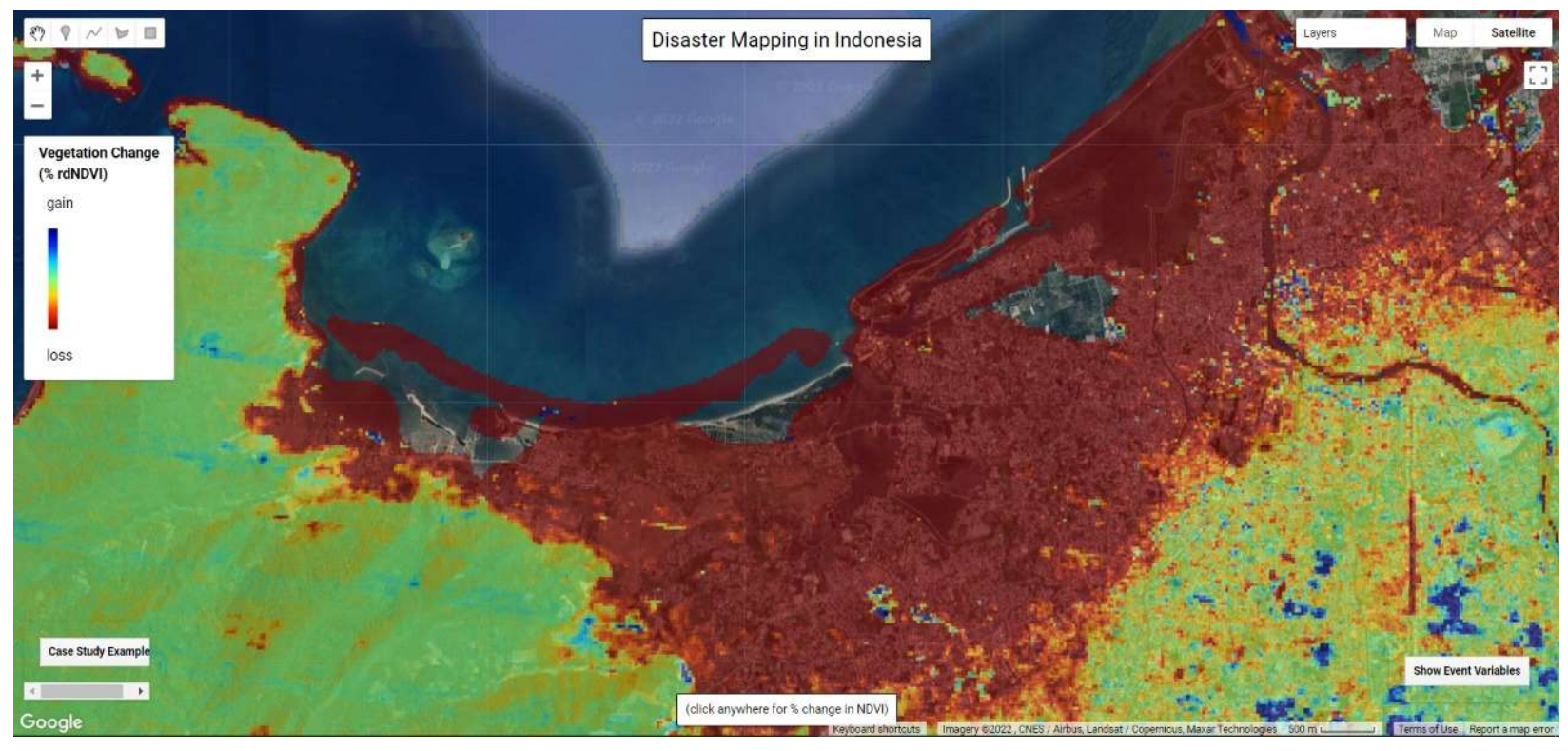

Figure 2. Resulted mapping of disaster affected areas in Banda Aceh City, during tsunami on December 26, 2004. Red areas indicated vegetation loss between 12 months pre and post-event. 


\subsection{Earthquake in Palu}

In 2018 earthquake with a magnitude of 7.5 Ritcher scale impacted the west coast of Sulawesi Island, Indonesia, and was followed by tsunami. Palu City is one of Indonesia's most seismically active locations since it is crossed by the Palu to Koro fracture, and has the potential to trigger large earthquakes. The earthquake and tsunami that struck Palu City on September 28, 2018 led to severe damage along the shore, particularly on the Lere Coast of Palu City ( Fauzi, 2021). In this event, HazMapper was used to track vegetation loss. Along the coast to the narrowing river, a large rdNDVI percentage reduction was captured (Figure 3).

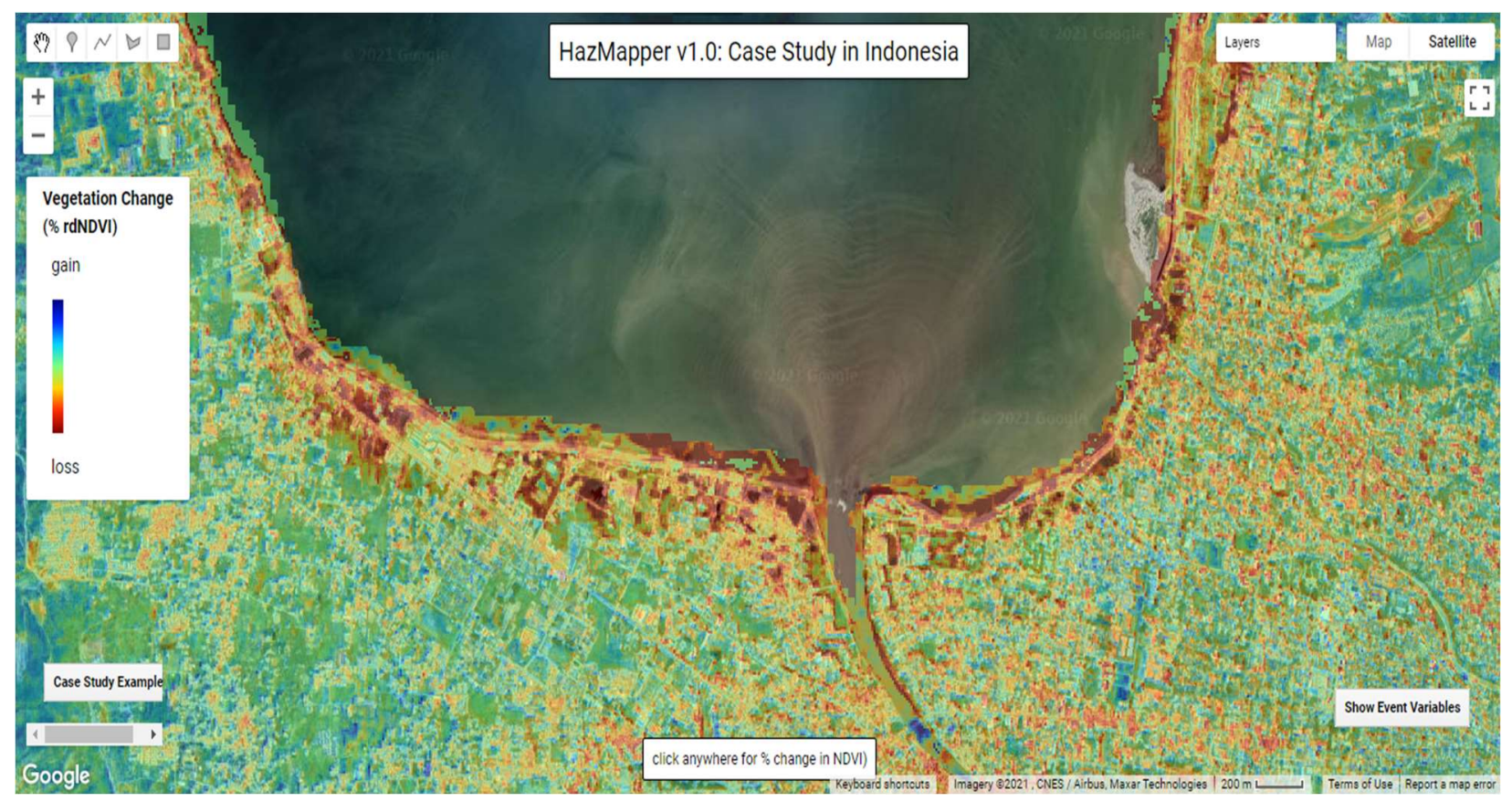

Figure 3. Resulted mapping of disaster affected areas in Palu City, during tsunami on September 28, 2018. Red areas indicated vegetation loss between 1 month pre and post-event.

\subsection{Earthquake in Yogyakarta}

A 5.9 Richter scale earthquake hit Java island in 2006. The epicenter was about 37 kilometers south from the city Yogyakarta limits. The earthquake heavily damaged housing and infrastructure in eight districts across Yogyakarta province and neighboring Central Java province. Water and sanitation facilities were also severely damaged; 164,000 household wells must be cleaned or restored, and 155,000 latrines must be renovated or rebuilt. (2008, Gulzar).

Grogol Weru is one of the locations affected by the earthquake. (Figure 4) The earthquake occurred at around 05:55 WIB with a vibration of approximately 59 seconds Weru. (Ristianingsih, 2014). The percentage of rdNDVI loss was spread across the region with diverse severity. However, there is a vegetation gain for a period of 1 month after the earthquake which is marked with blue rdNDVI in some areas, because the post event image was greener than the pre event. 
This indicates that there is vacant land that has become an area of vegetation which did not exist a month before the earthquake occurred.

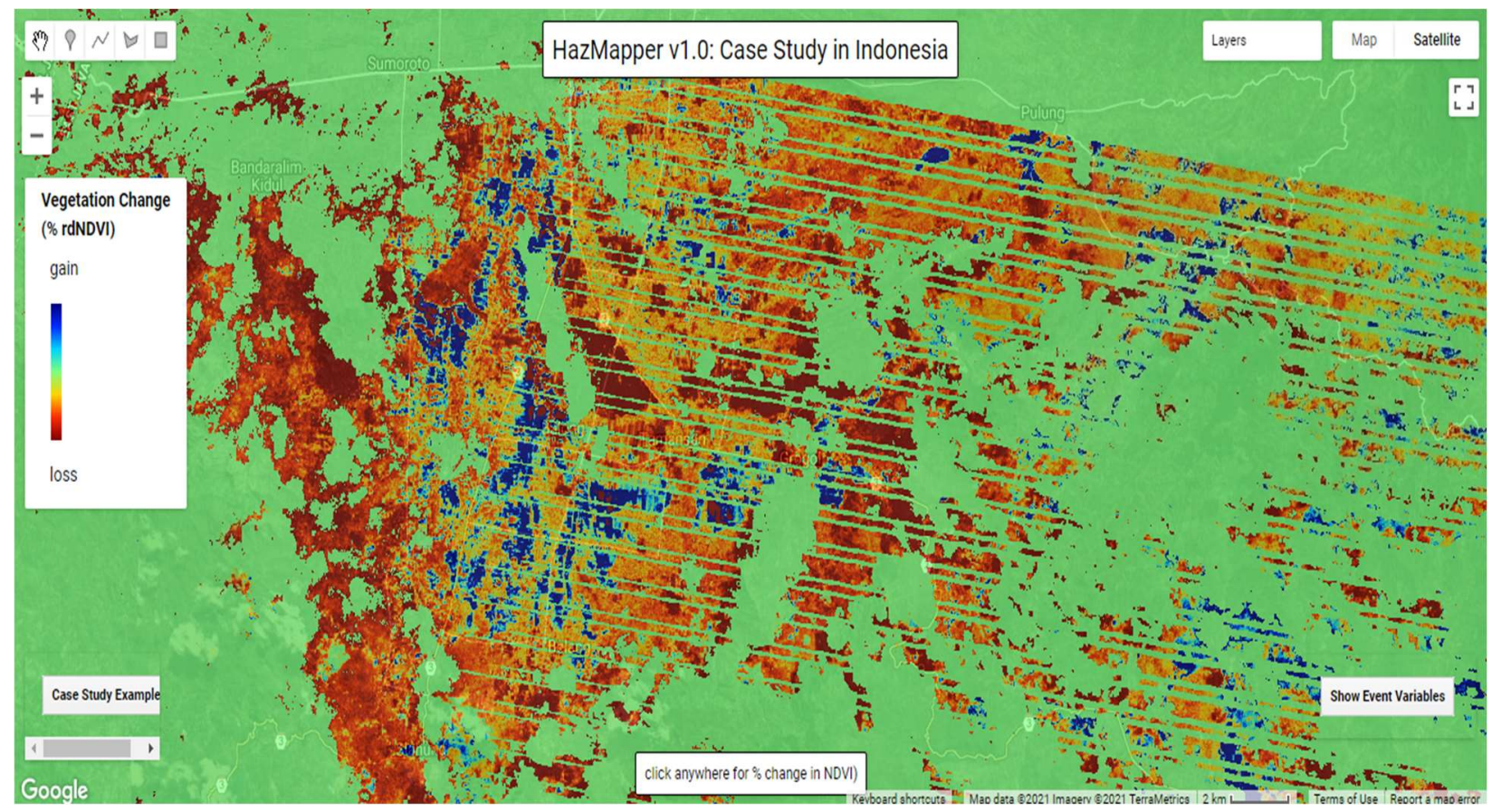

Figure 4. Resulted mapping of disaster affected areas in Yogyakarta City, during earthquake on May 27, 2006. Red areas indicated vegetation loss between 1 month pre and post-event.

\section{DISCUSSION}

\subsection{Limitation}

By the time this study is authored, HazMapper's capabilities are restricted to identification and mapping. User-driven semi-automation techniques leveraging machine learning for landslide diagnosis in HazMapper are currently being developed and will be detailed in a future publication. HazMapper's underlying datasets allow users to limit the duration of an event to $\geq 5 \mathrm{~d}$ (Sentinel2) or $\geq 16 \mathrm{~d}$ (Landsat)Imagery is normally available on GEE within 24 hours of the satellite collecting it. HazMapper only works with datasets that are publicly accessible through the GEE Data Catalog. Although many researchers have the resources to utilize the usage of near-daily datasets, HazMapper still needs to find a mechanism for absorbing these data.

The spatial reach of processing and data downloads are two major restrictions. Continental scale analysis alone is not possible, even with the platform's vast levels of processing power. As users attempting to analyze any broad area, it frequently results in long wait periods for data or data failure in HazMapper. Similarly, Google limits current external user downloads to $32 \mathrm{MB}$. In Sentinel-2 data ( $10 \mathrm{~m}$ pixel resolution), the limit covers approximately $400 \mathrm{~km} 2$. When the download process is started, HazMapper provides a complete view dimension within the user's browser window. The download panel could not appear if the area is larger than $400 \mathrm{~km} 2$. While 
these conditions happen, the user could zoom in the image until reprocessing starts and downloadable data begins to appear. (Scheip, 2021)

\subsection{Parameters of the Event}

The event parameters panel is developed to support upon a wide range of natural disaster varieties, locations, and outcomes to be analyzed. The GUI design and URL adjusting are combined to facilitate rapid investigation of events with various parameter configurations in order to reveal the natural disaster. Table 1 lists the event parameters, and the following sections explain how to use them:

- Set of data. The parameter lets users to choose the dataset to analyze (Landsat 7, Landsat 8, or Sentinel-2).

- The date of the event. The event date is used to define the pre to post periods for which the rdNDVI computation should be performed.

- The length of the windows. The length of a window is measured in months, and it can be adjusted to capture more or less data before or after an event.

- The maximum amount of cloud cover. This parameter's purpose is to speed up processing by excluding any photos with cloud cover larger than the input parameters.

- Threshold for a slope. During the visualization phase, the lowest slope level for analysis is applied to filter off areas with low slope.

\subsection{Recommended Applications}

In addition to the experiments detailed here, HazMapper could be beneficial in a variety of other situations. For example, during massive mass-wasting events, vegetation can be used as a proxy for reducing hazard (Shen et al., 2020; Yunus et al., 2020). This regrowth may be monitored and quantified by adjusting parameters in HazMapper. Categorizing agricultural or logging activities (includes tracing unlawful activities), tracking prescribed burns as well as the growth of early successional species, and natural pest detection are some of the other applications.

\subsection{Long Run Work}

Normalized Difference Built-Up Index (NDBI) can be used as an alternative metric for non-vegetational regions such as cities, and industrial areas. As an example, flood patterns in DKI Jakarta that can be recognized in order to improve flood mitigation and preparedness. HazMapper has a lot of room for improvement, especially in disaster risk management.

\section{CONCLUSION}

The use of rdNDVI for the identification of natural disasters in Indonesia is an effective and efficient breakthrough, especially in mapping disaster-affected areas that have a dominant 
green vegetation environment. Case study in Indonesia as geological condition of the region which makes Indonesia a country that is prone to disasters, lead to an essential disaster risk management using remote sensing technology, particularly satellite images prior to identification and mapping of natural disaster events. Tsunami events in Aceh and Palu, as well as the earthquake in Yogyakarta, are two good instances of how to use HazMapper to track landscape changes caused by the destruction or regeneration of terrestrial vegetation following a natural disaster. HazMapper is a community oriented open-source project aimed at making data analysis for natural disaster risk identification and mapping more accessible. Our resulted disaster mapping in Indonesia from satellite imagery data using the modified version of HazMapper used in this study is publicly accessible at https://s.id/IndonesiaDisasterMapping

\section{REFERENCES}

BNPB (2015). Kajian Risiko 2016-2020. https://inarisk.bnpb.go.id/pdf/ACEH/Dokumen\%20KRB\%20Prov.\%20ACEH_final\%20dr aft.pdf

Ge, G., Gokon, H., Meguro, K. (2020). A review on synthetic aperture radar-based building damage assessment in disasters. Remote Sensing of Environment, 240, 111693. https://doi.org/10.1016/j.rse.2020.111693.

Gulzar, Keyim. (2008). Case Study-Yogyakarta and Central Java Earthquake 2006. UNDP. https://www.recoveryplatform.org/assets/irp_case_studies/irp-cs-28-idn.pdf

Kucharczyk, M., Hugenholtz, C. H. (2021). Remote sensing of natural hazard-related disasters with small drones: Global trends, biases, and research opportunities. Remote Sensing of Environment, 264, 112577. https://doi.org/10.1016/j.rse.2021.112577.

Liu, C. C., Shieh, M. C., Ke, M. S., \& Wang, K. H. (2018). Flood prevention and emergency response system powered by Google Earth Engine. Remote Sensing, 10(8). https://doi.org/10.3390/rs10081283

Nurmasari, Y., Wijayanto, A. W. (2021). Oil Palm Plantation Detection in Indonesia using Sentinel-2 and Landsat-8 Optical Satellite Imagery (Case Study: Rokan Hulu Regency, Riau Province). International Journal of Remote Sensing and Earth Sciences, 18(1), 1-18. LAPAN. http://dx.doi.org/10.30536/j.ijreses.2021.v18.a3537

Putri, S. R., Wijayanto, A. W. (2021). Learning Bayesian Network for Rainfall Prediction Modeling in Urban Area using Remote Sensing Satellite Data (Case Study: Jakarta; Indonesia). In Proceedings of The International Conference on Data Science and Official Statistics,77-90. https://doi.org/10.34123/icdsos.v2021i1.37

Ristianingsih, Desy Erny. (2014). Pengetahuan Mitigasi Bencana Gempabumi Siswa Kelas VIII di SMP Muhammadiyah Grogol Weru Kabupaten Sukoharjo. http://eprints.ums.ac.id/31136/13/NASKAH_PUBLIKASI.pdf 
Robinson, N. P., Allred, B. W., Jones, M. O., Moreno, A., Kimball, J. S., Naugle, D. E., Erickson, T. A., \& Richardson, A. D. (2017). A dynamic landsat derived normalized difference vegetation index (NDVI) product for the conterminous United States. Remote Sensing, 9(8), 1-14. https://doi.org/10.3390/rs9080863

Rosyidie, Arief. (2006). Dampak Bencana Terhadap Wilayah Pesisir: Belajar dari Tsunami Aceh. In Journal of Regional and City Planning (Vol. 17, Issue 3, pp. 63-81). https://journals.itb.ac.id/index.php/jpwk/article/view/4246

Saadi, T. D. T., Wijayanto, A. W. (2021). Machine Learning Applied to Sentinel-2 and Landsat-8 Multispectral and Medium-Resolution Satellite Imagery for the Detection of Rice Production Areas in Nganjuk, East Java, Indonesia,International Journal of Remote Sensing and Earth Sciences, 18(1), 19-32. LAPAN. http://dx.doi.org/10.30536/j.ijreses.2021.v18.a3538

Scheip, C., \& Wegmann, K. (2020). HazMapper: A global open-source natural hazard mapping application in Google Earth Engine. Natural Hazards and Earth System Sciences Discussions, 1-25. https://doi.org/10.5194/nhess-2020-108

Triscowati, D. W., Sartono, B., Kurnia, A., Dirgahayu, D., \& Wijayanto, A. W. (2020). Classification of Rice-Plant Growth Phase using Supervised Random Forest Method based on Landsat-8 Multitemporal Data. International Journal of Remote Sensing and Earth Science,16(2), 83-94. LAPAN. http://dx.doi.org/10.30536/j.ijreses.2019.v16.a3217

Triscowati, D. W., Sartono, B., Kurnia, A., Domiri, D. D. \& Wijayanto, A. W. (2019). Multitemporal remote sensing data for classification of food crops plant phase using supervised random forest. In Proceedings of the SPIE. Sixth Geoinformation Science Symposium, 11311, 1131102. International Society for Optics and Photonics. https://doi.org/10.1117/12.2547216

Wijayanto, A. W., Triscowati, D. W., \& Marsuhandi, A. H. (2020). Maize field area detection in East Java, Indonesia: An integrated multispectral remote sensing and machine learning approach. In Proceedings of 2020 12th International Conference on Information Technology and Electrical Engineering (ICITEE), 2020, pp. 168-173. 10.1109/ICITEE49829.2020.9271683. 